\title{
BMJ Open Cohort profile: Center for Research on Early Childhood Exposure and Development in Puerto Rico
}

\author{
Justin Manjourides (iD , ${ }^{1}$ Emily Zimmerman, ${ }^{2}$ Deborah J Watkins, ${ }^{3}$ \\ Thomas Carpenito, ${ }^{1}$ Carmen M Vélez-Vega, ${ }^{4}$ Gredia Huerta-Montañez, ${ }^{5}$ \\ Zaira Rosario, ${ }^{4}$ Ishwara Ayala, ${ }^{4}$ Carlos Vergara, ${ }^{4}$ Zlatan Feric, ${ }^{5}$ Martha Ondras, ${ }^{6}$ \\ Helen H Suh, ${ }^{6}$ April Z Gu, ${ }^{7}$ Phil Brown, ${ }^{1,8,9}$ José F Cordero, ${ }^{4,10}$ John D Meeker, ${ }^{3}$ \\ Akram Alshawabkeh ${ }^{5}$
}

To cite: Manjourides J, Zimmerman E, Watkins DJ, et al. Cohort profile: Center for Research on Early Childhood Exposure and Development in Puerto Rico. BMJ Open 2020;10:e036389. doi:10.1136/ bmjopen-2019-036389

- Prepublication history for this paper is available online. To view these files, please visit the journal online (http://dx.doi org/10.1136/bmjopen-2019036389).

Received 16 December 2019 Revised 23 March 2020 Accepted 28 May 2020

\section{Check for updates}

(C) Author(s) (or their employer(s)) 2020. Re-use permitted under CC BY-NC. No commercial re-use. See rights and permissions. Published by BMJ.

For numbered affiliations see end of article.

Correspondence to Dr Justin Manjourides; j.manjourides@northeastern.edu

\section{ABSTRACT}

Purpose Puerto Rican children experience high rates of asthma and obesity. Further, infants born in Puerto Rico are more at risk for being born prematurely compared with infants on the mainland USA. Environmental exposures from multiple sources during critical periods of child development, potentially modified by psychosocial factors, may contribute to these adverse health outcomes. To date, most studies investigating the health effects of environmental factors on infant and child health have focused on single or individual exposures.

Participants Infants currently in gestation whose mother is enrolled in Puerto Rico Testsite for Exploring Contamination Threats (PROTECT) cohort, and infants and children already born to mothers who participated in the PROTECT study.

Findings to date Data collection and processing remains ongoing. Demographic data have been collected on 437 mother-child pairs. Birth outcomes are available for 420 infants, neurodevelopmental outcomes have been collected on 319 children. Concentrations of parabens and phenols in maternal spot urine samples have been measured from 386 mothers. Center for Research on Early Childhood Exposure and Development mothers have significantly higher urinary concentrations of dichlorophenols, triclosan and triclocarban, but lower levels of several parabens compared with reference values from a similar population drawn from the National Health and Nutrition Examination Survey.

Future plans Data will continue to be collected through recruitment of new births with a target of 600 children. Seven scheduled follow-up visits with existing and new participants are planned. Further, our research team continues to work with healthcare providers, paediatricians and early intervention providers to support parent's ability to access early intervention services for participants.

\section{INTRODUCTION}

Puerto Rico faces numerous health challenges compared with the mainland USA. Puerto Rican children experience some of the highest asthma and obesity rates of any racial/ethnic group in the USA. ${ }^{1-4}$ In addition, infants born
Strengths and limitations of this study

- Innovative aims involving early-life exposure to phenols, parabens and mixtures and their relationship to fetal and child development.

- An at-risk and underserved population that will provide valuable information for public health policy and can generate hypothesis for future research.

- Access to rich datasets and samples from the ongoing cohort study.

- Study population is Hispanic and located in Puerto Rico, potentially impacting the generalisability of our results.

- Enrolment period overlapped with the Zika epidemic and several hurricanes, including Hurricane Maria in 2017.

in Puerto Rico are more at risk for being born prematurely compared with infants in the mainland $(11.50 \%$ vs $9.60 \%$, respectively, in 2017). ${ }^{56}$ Many studies are attempting to determine factors affecting Puerto Rico's high asthma and preterm birth rates. ${ }^{7-13}$ Maternal characteristics and behaviours play an important role, but cannot alone explain the high adverse health outcome rates in Puerto Rico. Other factors, such as exposures to environmental pollutants and contaminants of emerging concern (CEC) (chemicals present in the environment that have not been previously detected, or were detected in much lower concentrations ${ }^{14}$ ), have been implicated as important contributors. Environmental contamination in Puerto Rico is extensive, with 200+ hazardous waste sites including 16 active Superfund sites-polluted locations requiring a long-term response to clean up hazardous material contaminations-and many contaminated water resources. ${ }^{15}$ In particular, prenatal exposure to air pollution has been linked to adverse 


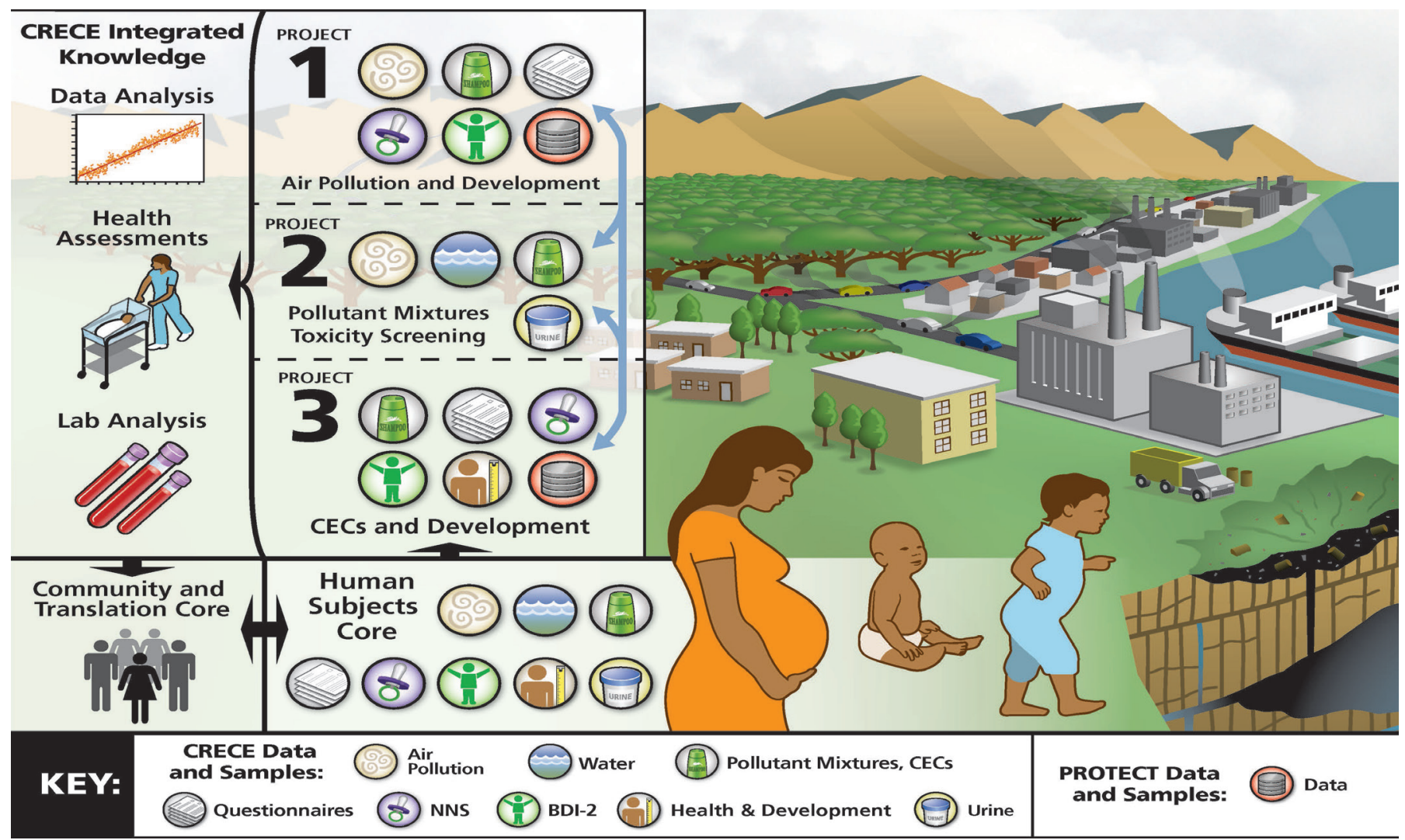

Figure 1 CRECE research programme schematic. BDI-2, Battelle Developmental Index-2; CECs, contaminants of emerging concern; CRECE, Centre for Research on Early Childhood Exposure and Development; NNS, non-nutritive suck; PROTECT, Puerto Rico Testsite for Exploring Contamination Threats.

birth outcomes ${ }^{16-25}$ and, to a lesser extent, developmental delays, ${ }^{26-29}$ even for populations living in areas that meet air quality standards. Among these factors is Puerto Rico's numerous and varied air pollution sources, including traffic congested streets, petrochemical refineries, incinerators, power plants, large maritime ports receiving diesel powered cruise ships and air currents carrying Saharan dust. Though in utero exposures to CECs may contribute to adverse developmental outcomes, ${ }^{30}{ }^{31} \mathrm{few}$ human studies to date have focused on the possible link between these CECs, endocrine disruption and child health outcomes in Puerto Rico. ${ }^{32-34}$

To date, most studies investigating the health effects of environmental factors on infant and child health have focused on single or individual exposures such as lead, ${ }^{35-37}$ chemicals in personal care products, ${ }^{31} 3839$ poverty, ${ }^{41}$ stress ${ }^{42-44}$ and air pollution. ${ }^{45-47}$ While these have contributed significant knowledge, they do not reflect the reality that children experience combinations of exposures simultaneously, such as poverty and pollution, ${ }^{48} 49$ or lead and stress, ${ }^{50} 51$ or poverty and stress. ${ }^{52} 53$ Further, they do not address other human and animal research showing that combinations of exposures at levels deemed 'safe' can produce mixture effects greater than could be predicted based on each exposure alone, ${ }^{5455}$ thereby inadequately capturing the exposure profiles and effects experienced by the population they are trying to describe.
Therefore, opportunities exist to explore the constellation of risk factors including demographic, adverse birth outcomes and environmental exposures and their influence over child development in Puerto Rico. Understanding the modifying factors involved is critical to the development of interventions and policies to improve the health and well-being of Puerto Rico's children.

\section{Cohort description}

The Center for Research on Early Childhood Exposure and Development in Puerto Rico (CRECE) is a Children's Environmental Health Center programme funded by the US Environmental Protection Agency and the National Institute of Environmental Health Sciences (NIEHS). CRECE provides valuable new information on the impacts of multichemical environmental exposures, maternal stress and psychological factors on fetal and early childhood health and development, as well as the factors that may modify those impacts. CRECE leverages the rich dataset and the infrastructure established under the Puerto Rico Testsite for Exploring Contamination Threats (PROTECT, a Superfund Research Programme Center funded by NIEHS) to study a cohort of 600 children, whose prenatal exposures were documented in the PROTECT study, tracking them through age $4{ }^{56}$ Results from our center will potentially inform future preventive clinical intervention, risk assessment and policy-setting efforts and promote further research activities with 


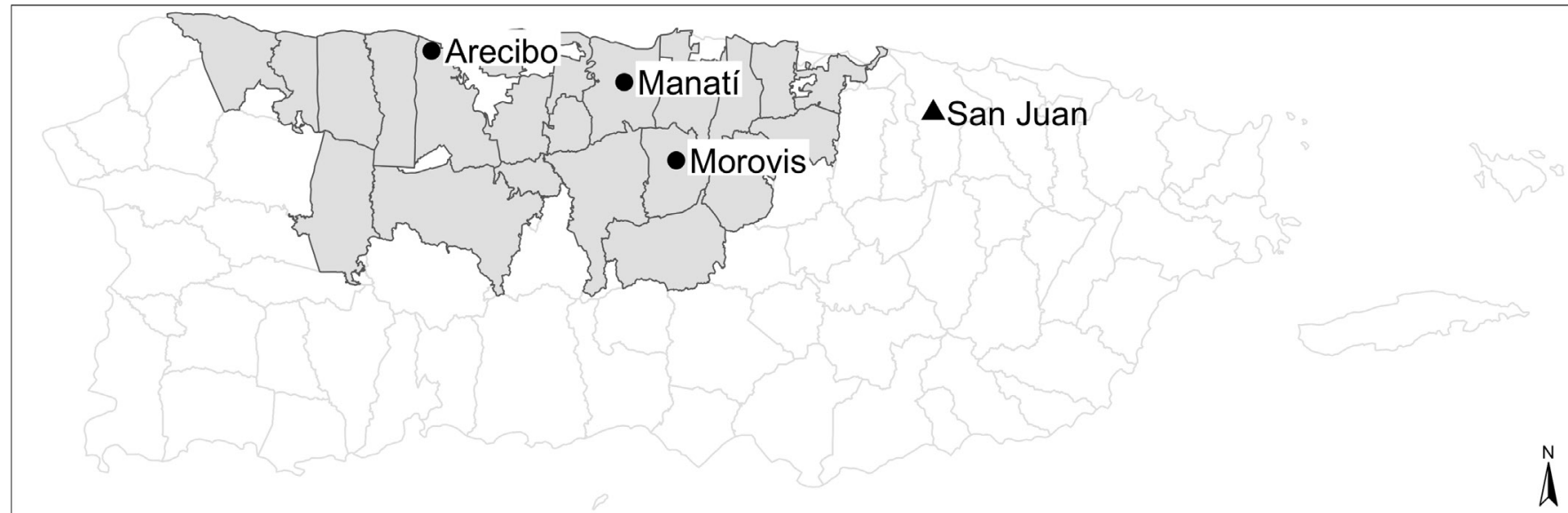

Figure 2 CRECE recruitment area and air pollution stationary ambient monitoring site locations of the three stationary ambientair quality monitors in Arecibo, Mantatí and Morovis. CRECE, Centre for Research on Early Childhood Exposure and Development.

direct relevance to both the underserved population of Puerto Rico, as well as certain segments of the US general population.

\section{Study aims}

CRECE was designed to provide valuable new information on the impacts of multichemical environmental exposures on fetal and early childhood health and development, as well as the factors that may modify those impacts. With a diverse group of researchers and clinicians (see figure 1), CRECE research projects couple air-pollution epidemiology (project 1), high-throughput toxicity screening of multimedia pollutant mixtures (project 2) and biomarker epidemiology (project 3) to analyse the impacts of early life exposure (both specific stressors and mixture effects) on fetal/child health and development, taking into account environmental, clinical, social, demographic, behavioural, dietary and other factors. Through CRECE's centralised Human Subjects Core, observed, self-reported and biological measures are taken, providing new information characterising the early life exposures to air and water pollution, including CECs. Importantly, CRECE also leverages detailed data on prenatal conditions of the pregnant mothers collected under PROTECT, including not only their chemical exposures but also their nutrition, personal habits and socioeconomic characteristics, thus allowing us to examine the combined influences of multiple environmental, nutritional and social factors on child health. Lastly, CRECE engages stakeholders through its Community Outreach and Translation Core (COTC) to support environmental health practice, innovation and policy, professional development and to spread awareness of CRECE's work to the general public.

\section{Study population}

Participant recruitment and informed consent

CRECE is an observational prospective cohort study. Eligible study subjects include infants currently in gestation whose mother is enrolled in PROTECT, and infants and children already born to mothers who participated in the PROTECT study.

\section{The protect study enrolment}

PROTECT study participants were recruited on the island's northern coast (figure 2) at two collaborating hospitals, Manatí Medical Center, and Arecibo's Cayetano Coll y Toste Hospital, and five health clinics located in Camuy, Lares, Morovis, Quebradillas and Ciales. Participants recruited at a health clinic intended to deliver at one of the two collaborating hospitals.

Pregnant women visiting a participating clinic or hospital at approximately 14 weeks gestation were eligible for inclusion into the PROTECT study if they were between the ages of 18 and 40 years, reside in a municipality in the northern Karst region of the island, did not use oral contraceptives for at least 3 months prior to becoming pregnant, did not use in vitro fertilisation to become pregnant, and were free of known medical or obstetrical complications, including diabetes. ${ }^{56}$ Eligible women were invited to participate and asked to provide informed consent.

An initial screening form gathering information on demographic characteristics and to estimate date of last menstrual period was collected at the time of enrolment. Subsequently, women were invited to participate in three study visits targeted for $20 \pm 2$ weeks gestation, $24 \pm 2$ weeks and $28 \pm 2$ weeks. At delivery, pregnancy outcome along with birth weight and other newborn measurements was collected.

Of 2259 eligible women, our team has recruited 2074 $(91.8 \%)$ into the PROTECT study. We have currently observed 1598 pregnancy outcomes, including 1513 live births, 225 pregnancies in progress and 251 withdrawals.

\section{CRECE study enrolment}

PROTECT participants are informed about the CRECE study during their third visit at $28 \pm 2$ weeks gestation. The PROTECT nurse informs the participant about the 
study and the possibility of their baby's participation as part of the CRECE cohort. They are given a one-page (front and back) fact sheet that describes the study purpose and what is expected of study participants in terms of encounters with study staff, interviews and the different tests and questionnaires that are performed at each visit.

Once the PROTECT participant delivers, they receive a letter, phone call and/or electronic message from PROTECT staff informing them of their child's eligibility to participate in CRECE. Once the mother and the infant are discharged from the hospital, CRECE staff contact the mother within the first week after delivery to remind her about the CRECE study. If she is still interested, an appointment is arranged to discuss participation, and, if the mother agrees to participate, she is presented with the informed consent document, which includes asking permission for the abstraction of information from the child's birth and medical records. In the case of older children born to PROTECT mothers who are younger than 4 years of age, the recruitment process and the first CRECE evaluation is conducted at any age that fits within our study window.

Recruitment and follow-up visits are conducted at the PROTECT/CRECE office, located across from the Manatí Medical Center. This site is centrally located within the catchment area of the study participants' homes. This office space has four examining rooms, a waiting room, restroom area, an office space and a locked room to store file cabinets and confidential study documents. For participants who receive primary healthcare services for their children and families in one of the Federally Qualified Community Health Centres (Morovis Community Health Centre, Ciales- PryMed and Centro de Salud Lares or Camuy Health Services), the follow-up visits may be conducted at that centre to overcome any transportation issues.

The study consists of seven clinical evaluations of study participants beginning between 2 and 6 weeks. At the initial visit infants are evaluated at the CRECE clinic or at health centre where they receive their primary healthcare. Depending on the participant's age, the evaluation completed by a paediatrician consists of a complete physical examination, including standard measurements of height, weight, head circumference, assessment of anogenital distance (AGD), the non-nutritive suck measurement (NNS), optoacoustic hearing emission test and a neurodevelopmental evaluation using diverse development assessment tools. Subsequent follow-up visits are conducted according to the infant and child assessments described below.

Out of all PROTECT births, 1513 were eligible for recruitment to CRECE. However, because the CRECE study began in 2016, there were 430 babies born to PROTECT enrolled mothers that had already aged out of the CRECE study. From the 1083 births that met the recruitment criteria and were still younger than 4 years old at the start of CRECE in 2016, $555(51 \%)$ were recruited and enrolled into the CRECE cohort and 23 $(4 \%)$ have withdrawn from the study.

There are two main factors influencing the recruitment success of CRECE. First, the location of the PROTECT participant influenced recruitment, as those mothers seen at clinics further from the CRECE clinic in Manatí (such as those from clinics in Camuy, Lares, and Quebradillas) were less likely to enrol. Second, child age was a factor as mothers of older children (though still less than 4 years of age) had been out of the PROTECT study longer, and their contact information may have changed.

\section{Follow-up visits}

CRECE children have seven follow-up visits at the following time points: 2-6 weeks, $6-8$ months, 12 months, 18 months, 2 years, 3 years and 4 years (see table 1 ).

\section{Patient and public involvement}

Though no funds were allocated for patient and public involvement, the CRECE programme benefits from the work of the PROTECT CEC. The PROTECT CEC works with an advisory committee that includes healthcare providers from the federally qualified health clinics where our participants receive primary health services. The CEC also gets feedback from an advisory group where participants that have been a part of PROTECT and CRECE provide input on community engagement activities including report back of results. The report-back platform was developed in close work with these community advisors. Further details are provided below in the COTC and parent engagement section.

\section{Measurements}

Parent questionnaire

The Parental Interview Questionnaire includes questions on the following areas: sociodemographics, birth history, child's medical history, feeding and sleep habits, respiratory symptoms, environmental exposures, maternal stress (the Perceived Stress Scale with permission of the American Sociological Association ${ }^{57}$ ), and maternal depression (from the Centre for Epidemiological Studies Depression Scale. This questionnaire also evaluates the area of social support adapting the ENRICHD Social Support Inventory (ESSI). The ESSI is a seven-item scale composed of items found to be individually predictive of mortality in cardiac patients and items from other well-validated social support scales. ${ }^{58}$ The ESSI includes items which primarily measure functional support, and in particular, emotional support. The ESSI is used both as a screening tool to determine patients' perceived social support, and to assess changes in patients' social support during treatment (at 6-month and 12-month follow-ups) and following the intervention (at the 18-month follow-up visit and annually thereafter).

\section{Physical exams}

During all but the 18-month-old evaluation, a paediatrician certified by the American Board of Pediatrics performs a physical examination that follows the evidence-based principles, strategies and tools recommended by the 
Table 1 Follow-up schedule for CRECE cohort

CRECE follow-up schedule

\begin{tabular}{|c|c|c|c|c|c|c|c|}
\hline & $\begin{array}{l}\text { 2-6 } \\
\text { weeks }\end{array}$ & 6-8 months & $\begin{array}{l}12 \\
\text { months }\end{array}$ & 18 months & $\begin{array}{l}2 \\
\text { years }\end{array}$ & $\begin{array}{l}3 \\
\text { years }\end{array}$ & $\begin{array}{l}4 \\
\text { years }\end{array}$ \\
\hline Parent Questionnaire & $\checkmark$ & $\checkmark$ & $\checkmark$ & & $\checkmark$ & $\checkmark$ & $\checkmark$ \\
\hline $\begin{array}{l}\text { Anthropometric } \\
\text { measurements }\end{array}$ & $\checkmark$ & $\checkmark$ & $\checkmark$ & $\checkmark$ & $\checkmark$ & $\checkmark$ & $\checkmark$ \\
\hline $\begin{array}{l}\text { Ages and Stages } \\
\text { Questionnaire third ed }\end{array}$ & $\checkmark$ & $\checkmark$ & $\checkmark$ & $\checkmark$ & $\checkmark$ & $\checkmark$ & $\checkmark$ \\
\hline $\begin{array}{l}\text { Ages and Stages } \\
\text { Questionnaire Social- } \\
\text { Emotional second ed }\end{array}$ & $\checkmark$ & $\checkmark$ & $\checkmark$ & $\checkmark$ & $\checkmark$ & $\checkmark$ & \\
\hline $\begin{array}{l}\text { Battelle Developmental } \\
\text { Inventory second ed }\end{array}$ & & & $\checkmark$ & & $\checkmark$ & $\checkmark$ & $\checkmark$ \\
\hline $\begin{array}{l}\text { Modified Checklist for } \\
\text { Autism in Toddlers }\end{array}$ & & & & $\checkmark$ & & & \\
\hline $\begin{array}{l}\text { Child behavioural } \\
\text { checklist }\end{array}$ & & & & $\checkmark$ & $\checkmark$ & $\checkmark$ & $\checkmark$ \\
\hline
\end{tabular}

CRECE, Centre for Research on Early Childhood Exposure and Development.

American Academy of Pediatrics for the paediatric well child visit evaluation. This physical examination includes all organ systems: head and neck; eyes, mouth, ears and nose; lungs and thorax; cardiovascular; abdomen; musculoskeletal; neurologic and genitourinary with special attention to the neurological system.

\section{Infant anthropometry}

Length/height, weight and head circumference measurements are collected at each study visit.

\section{AGD and anoscrotal distance}

AGD is a marker of in utero androgenic activity among infants. ${ }^{5960}$ AGD and anoscrotal distance (ASD) measurements are made while the infant is placed supine on the examining surface. The examiner positions him/herself in front of the baby and measures AGD and ASD (males) or AGD1 and AGD2 (girls) using digital Vernier callipers. In males, AGD is measured from the centre of the anus to the cephalad base of the penis and ASD is measured from midanus to the base (inferior aspect) of the scrotum. In girls, AGD1 is measured from mid-anus to the anterior clitoral surface and AGD2 is measured from mid-anus to the posterior fourchette.

Penile width, length and other endpoints: Penile width (diameter) is measured at the base of the penis with digital callipers while the penis is flaccid. Penile length is measured from the base of the phallus to the tip of the glans with digital callipers using standard stretched length technique. Testicular location is scored separately for left and right testis as: (1) Normal-scrotal (testis is located at or below the border between the upper and lower part of the scrotum; (2) Normal-retractile (testis can be pulled to the bottom of the scrotum and it remains there for a few seconds without further traction); (3) High scrotal (testis is located at the upper part of the scrotum) and (4) Suprascrotal (testis is located above the scrotum). Genital abnormalities such as hypospadias and cryptorchidism are also recorded

\section{Environmental exposures}

Air pollution

Week-long integrated samples of fine particles $\left(\mathrm{PM}_{2.5}\right)$ are collected on Teflon filters using cascade impactors assembled for the project, at three stationary ambient monitoring (SAM) sites on the north coast of Puerto Rico (figure 2). Sites are the PROTECT/CRECE clinic in Manati, the Community Health Centre in Morovis, and two sites near the Universidad del Este Centro in Arecibo. Sampling has been continuous at the Manati and Morovis sites since June 2016, except for several 
months of interruption due to hurricanes Irma and Maria in 2017-2018.

Samples are reviewed for quality control, and field technicians use flow metres (mini-Buck Calibrator, by A P Buck, Florida, USA) to record the flow before and after each filter is sampled. Sampled filters are marked void when flow rate change is greater than $10 \%$, filters are damaged, or sampling time is disrupted.

Gravimetric $\mathrm{PM}_{2.5}$ analysis is performed by Harvard TH Chan School of Public Health Department of Environmental Health (HSPH-EH), including filter preparation, presampling and postsampling weighing and quality control/assurance.

Reflectance analysis of Black Carbon is also performed at the HSPH-EH, using an EEL (Incorporating Evans Electroselenium) smoke stain reflectometer (Model 43D; Diffusion Systems, London, UK). Absorbance is calculated using a modified published method. ${ }^{61}$

Samples are analysed at the HSPH-EH by X-ray fluorescence (PANalytical Epsilon 5 EDXRF spectrophotometer; Almelo, The Netherlands) for 48 elements.

$\mathrm{PM}_{2.5}$ exposures were estimated for each baby in the CRECE cohort as the measured concentration at the SAM closest to the mother's municipality of residence at the time of birth.

We employ a recently developed quantitative molecular toxicity endpoint-Protein Effect Level Index (PELI) and Transcriptional Effect Level Index (TELI), which quantify the cumulative effects of the mixture chemicals on specific pathways relevant to CRECE adverse health outcomes, measured through high-throughput screening of Green fluorescent protein (GFP)-tagged yeast cells and human lung cells.

\section{Water contamination}

Water contamination in tap water is assessed using a quantitative toxicogenomics HTS assay to quantify and characterise the oxidative stress, DNA repair and inflammation pathway perturbation resulting from exposure to mixtures of CEC, metals and other pollutants in tap water samples taken from the study area and participants in the north coast of Puerto Rico. Drinking water contains a large number of regulated and unregulated contaminants from various environmental pollution sources, as well as from water treatment processes. In the past decade, there has been increased concern about the large number of CEC, that are near-ubiquitous in various water sources. We focus on oxidative stress, DNA damage and inflammation because they are among the recognised pathways that may result in CRECE-relevant neonatal and early childhood health outcomes such as preterm birth and neurodevelopmental delays. In addition, tap water samples are subjected to targeted and suspect screening for 234 organic micropollutants including CECs and PR human exposure-relevant chemicals on high-resolution Liquid Chromatography Mass Spectrometry (LC-MS).

For both air and water contaminant exposures, we employ a recently developed quantitative molecular toxicity endpoint-PELI and TELI, which quantifies the cumulative effects of the mixture chemicals on specific pathways relevant to CRECE adverse health outcomes, measured through high-throughput screening of GFPtagged yeast cells and human lung cells.

\section{Contaminants of emerging concern}

Concentrations of phenols and parabens, chemicals often used in a range of consumer goods, including personal care products, plastics, packaged foods and pharmaceuticals $^{62}$ are measured in maternal spot urine samples collected at prenatal visits 1, 2 and 3 of the PROTECT study. Measured parabens include butylparaben, ethylparaben (EPB), methylparaben (MPB), and propylparaben (PPB). Measured phenols include bisphenol A, bisphenol $\mathrm{S}$, bisphenol F (BPF), 2,4-dichlorophenol (24-DCP), 2,5DCP (25-DCP), benzophenone-3, triclosan (TCS) and triclocarban (TCC).

\section{Neurodevelopment}

Developmental screening, using diverse developmental tools, is recommended by the American Academy of Pediatrics (AAP) ${ }^{63}$ Therefore, we selected a diverse and culturally appropriate set of developmental batteries to offer during our follow-up. The complete evaluation takes 1.5-2 hours (depending on the participant's age), including the interviews and self-administered questionnaires.

\section{Otoacoustic Emissions}

At the start of each study session, the child's hearing is screened using otoacoustic emissions testing using the GSI Corti (tm).

NNS is a physiological assessment of the infant's suck reflex, which can be indicative of central nervous system integrity. These data are collected in a subset of the participants using our user-friendly device that includes a Soothie pacifier attached to a pressure transducer that transmits information to a data acquisition system (Power Lab, ADInstruments) connected to a laptop with LabChart software (ADInstruments). We sample suck for approximately $5 \mathrm{~min}$, which yields the following NNS data: duration, frequency, amplitude, burst, cycles/burst, cycles/min.

Ages and Stages Questionnaires, Third Edition (ASQ-3) has been translated and standardised in Hispanic populations and it is the most widely used parent-completed questionnaires for young children in the USA. It has shown high sensitivity and specificity for detecting developmental delays. ${ }^{64}$ It evaluates developmental progress in children between the ages of 1 month to $5 \frac{1}{1 / 2}$ years and is the development screening instrument recommended by the Puerto Rico Department of Health under the Medicaid programme.

Ages and Stages Questionnaire

Social-Emotional, Second Edition (ASQ:SE-2) The ASQ: SE-2 are parent-completed questionnaires that reliably identify children age 1-72 months at risk for social or 
emotional difficulties by screening seven key behavioural areas-self-regulation, compliance, communication, adaptive functioning, autonomy, affect and interaction with people. These questionnaires are available in both English and Spanish.

\section{Battelle Developmental Index-2}

The Battelle Developmental Index-2 (BDI-2) is a comprehensive developmental assessment to evaluate children from birth through 7 years 11 months. It can be used to test individual domains or all 5 areas of development, in which case a general score is reported. The BDI-2 is norm-based (mean of 100 , SD of 15) on a nationally representative cohort that closely approximates the ethnic, geographic and socioeconomic composition of the US population. In addition, the BDI-2 has been translated to Spanish and has been used previously with Spanish-speaking cohorts, ${ }^{656}$ making it ideal for our study. Testing time for the complete BDI-2 can range from 1 hour to several hours according to the age and developmental level of the child.

\section{Modified Checklist for Autism in Toddlers, Revised with Follow-Up} The Modified Checklist for Autism in Toddlers (MCHAT) is a two-stage parent-report screening tool to assess risk for Autism Spectrum Disorder (ASD) in children between the ages of 16 and 30 months. The M-CHAT-R/F is available for free download for clinical, research and educational purposes. The MCHAT is one of the tools recommended by the AAP to screen children for autism at 18 and 24 months of age. The MCHAT is available in Spanish and is part of the Puerto Rico Department of Health Paediatric Preventive Guidelines.

\section{Child Behaviour Checklist}

The Child Behaviour Checklist is a school-age assessment scale for students ages $6-18$ years completed by the individual's parents or surrogates. It evaluates internalising and externalising behaviours and measures subareas including social withdrawal, somatic complaints, anxiety and depression, destructive behaviour, social problems, thought problems, attention problems, aggressive behaviour and delinquent behaviours.

\section{Eye tracking tasks: visual recognition memory and theory of mind} The visual recognition memory (VRM) task is based closely on work done by Rose $e t$ al who have shown that this task can assess infants' VRM, information-processing speed and control of attention. ${ }^{67}$ Rose's research also indicates that performance on this task in infancy is predictive of cognitive function in late childhood and adolescence. ${ }^{68}$ The theory of mind (TOM) task is a modified version of a paradigm developed by Kovacs $e t a l^{69}$ which suggests that the TOM task can be indicative of very early psychological reasoning (ie, the beginnings of the ability to infer other people's intentions and beliefs and use these inferences to predict their behaviour), which may be the foundation of later, more complex, social cognition functions. ${ }^{70}$

\section{Respiratory outcomes}

Respiratory health at birth is captured using the Apgar score, which is taken $1 \mathrm{~min}$ and $5 \mathrm{~min}$ after birth. The score ranges from 0 to 10 , and is based on respiratory effort, activity, pulse rate, appearance and reflex irritability. If the infant is born prematurely, we collect information regarding additional respiratory complications they may face during their Neonatal Intensive Care Unit (NICU) stay including respiratory distress syndrome and other neonatal complications. In addition, parents are asked to complete the CRECE Parental Questionnaire including a specific respiratory symptom section in which parents report on the frequency of doctor or hospital visits due to wheezy bronchitis, asthma, colds and influenza, feeding problems, throat infections, hay fever, vomiting and more. Additionally, the form includes questions relating to sleep, pets in the home, feeding and breathing difficulties and use of inhalers or prescription medications for breathing problems.

\section{Covariates}

CRECE also collects several demographic covariates that could potentially confound associations between environmental exposures and developmental outcomes. Sociodemographic factors include education, marital status, employment status and household income. Anthropomorphic factors include maternal age, prepregnancy body mass index (BMI), parity, gravidity, smoking status during pregnancy and alcohol use during pregnancy. Child-based factors include sex, gestational age at delivery and birth weight.

\section{Findings to date}

Current demographic results include 437 children born between 2011 and 2018 (table 2). Infant sex was available for 433 babies, of which $47 \%$ were female. Mean maternal age at enrolment was 28.11 years $(\mathrm{SD}=5.37, \mathrm{n}=417)$, and mean prepregnancy maternal BMI was $24.8 \mathrm{~kg} / \mathrm{m}^{2}$ $(\mathrm{SD}=5.59, \mathrm{n}=402)$. The observed average gestational age across all live births was 39.04 weeks $(\mathrm{SD}=1.76, \mathrm{n}=423)$ with an average birth weight of $3167 \mathrm{~g}(\mathrm{SD}=540, \mathrm{n}=342)$. Overall, we find no significant associations between these demographic characteristics and gestational age.

Full-term male and female babies had median Apgar scores of $9.00 \quad(\mathrm{n}=156)$ and 9.00, $(\mathrm{n}=145)$, respectively (table 3). Preterm male and female babies had median Apgar scores of $9.00(n=19)$ and $8.80(n=5)$, respectively. NNS outcomes are currently available for 168 infants, including 143 full-term and 4 preterm births. BDI scores taken between 11 and 14 months after birth are currently available for 81 infants ( 75 full term, 6 preterm).

$\mathrm{PM}_{2.5}$ levels in the North Shore of Puerto Rico are lower than their NAAQS measures and tend to be lower than those found in the conterminous US. $\mathrm{PM}_{2.5}$ concentrations vary seasonally, with levels higher during the warm as compared to cold season. Mean monthly exposure levels ranged between 6.9 and $7.2 \mu \mathrm{g} / \mathrm{m}^{3}$, with SDs of $\approx 2$ 
Table 2 Characteristics of 437 mothers and corresponding live births in the CRECE cohort (2011-2018)

\section{Mean/median (SD/range) or N}

(\%)

\begin{tabular}{|c|c|c|c|}
\hline \multirow{7}{*}{ Age at enrolment } & Overall mean & $28.1(5.4)$ & \\
\hline & Overall median & $28(18-40)$ & \\
\hline & $18-24$ & $117(27)$ & $38.83(1.82)(117)$ \\
\hline & $25-29$ & $140(32)$ & $39.13(1.7)(140)$ \\
\hline & $30-34$ & $101(23)$ & $39.02(2.06)(101)$ \\
\hline & $\geq 35$ & $64(15)$ & $39.25(1.16)(64)$ \\
\hline & Missing & $15(3)$ & $39(0)(1)$ \\
\hline \multirow{7}{*}{$\begin{array}{l}\text { Pre-pregnancy body mass } \\
\text { index }\end{array}$} & Overall mean & $25.5(5.60)$ & \\
\hline & Overall median & $24.8(11.6-49.1)$ & \\
\hline & $<18.5 \mathrm{~kg} / \mathrm{m}^{2}$ & $29(7)$ & $39.13(1.96)(29)$ \\
\hline & $18.5-24.9 \mathrm{~kg} / \mathrm{m}^{2}$ & $180(41)$ & $39.15(1.79)(180)$ \\
\hline & $25-29.9 \mathrm{~kg} / \mathrm{m}^{2}$ & $113(26)$ & $39.01(1.58)(113)$ \\
\hline & $>30 \mathrm{~kg} / \mathrm{m}^{2}$ & $80(18)$ & $38.88(1.98)(80)$ \\
\hline & Missing & $35(8)$ & $38.72(1.31)(21)$ \\
\hline \multicolumn{4}{|l|}{ Household income } \\
\hline & $<$ US\$20 000 & $164(38)$ & $38.96(1.82)(164)$ \\
\hline & US\$20 000-US\$39000 & $121(28)$ & $39.06(1.66)(121)$ \\
\hline & >US\$39 000 & $101(23)$ & $39.37(1.4)(101)$ \\
\hline & Missing & $51(12)$ & $38.39(2.45)(37)$ \\
\hline \multirow[t]{5}{*}{ Education level } & $<$ High school & $15(3)$ & $38.38(2.59)(15)$ \\
\hline & High school of equivalent & $37(8)$ & $38.75(1.34)(37)$ \\
\hline & College or technical school & $52(12)$ & $38.64(1.99)(52)$ \\
\hline & College degree or higher & $312(71)$ & $39.17(1.71)(312)$ \\
\hline & Missing & $21(5)$ & $38.9(1.63)(7)$ \\
\hline \multirow[t]{3}{*}{ Employment status } & Employed & $305(70)$ & $39.14(1.81)(305)$ \\
\hline & Not employed & $114(26)$ & $38.82(1.62)(114)$ \\
\hline & Missing & $18(4)$ & $37.82(1.09)(4)$ \\
\hline \multirow[t]{3}{*}{ Marital status } & Single & $60(14)$ & $38.79(1.89)(60)$ \\
\hline & Married or cohabitating & $358(82)$ & $39.09(1.74)(358)$ \\
\hline & Missing & $19(4)$ & $38.31(1.33)(5)$ \\
\hline \multirow{3}{*}{$\begin{array}{l}\text { Cigarette smoking during } \\
\text { pregnancy }\end{array}$} & Yes & $6(1)$ & $38.74(3.63)(6)$ \\
\hline & No & $410(94)$ & $39.05(1.73)(410)$ \\
\hline & Missing & $21(5)$ & $38.49(1.28)(7)$ \\
\hline \multirow{3}{*}{ Alcohol use during pregnancy } & Yes & $19(4)$ & $39.47(1.84)(19)$ \\
\hline & No & $400(92)$ & $39.03(1.75)(400)$ \\
\hline & Missing & $18(4)$ & $37.75(2.24)(4)$ \\
\hline \multirow[t]{3}{*}{ Gravidity } & $0-1$ previous pregnancies & $325(74)$ & $39.06(1.87)(325)$ \\
\hline & $>1$ previous pregnancies & $96(22)$ & $38.99(1.33)(96)$ \\
\hline & Missing & $16(4)$ & $37.36(1.11)(2)$ \\
\hline \multirow[t]{4}{*}{ Parity } & No previous births & $132(30)$ & $38.96(2.1)(132)$ \\
\hline & 1 previous birth & $149(34)$ & $38.95(1.84)(149)$ \\
\hline & $>1$ pevious birth & $52(12)$ & $39.01(1.3)(52)$ \\
\hline & Missing & $104(24)$ & $39.31(1.24)(90)$ \\
\hline
\end{tabular}
Mean (SD)(N) Mean (SD)(N) $28.1(5.4)$ $28(18-40)$ $117(27)$ $39.13(1.7)(140)$ $39.02(2.06)(101)$ (1.16)(64) 15 (3) 
Table 2 Continued

Mean/median (SD/range) or $\mathbf{N}$

(\%)

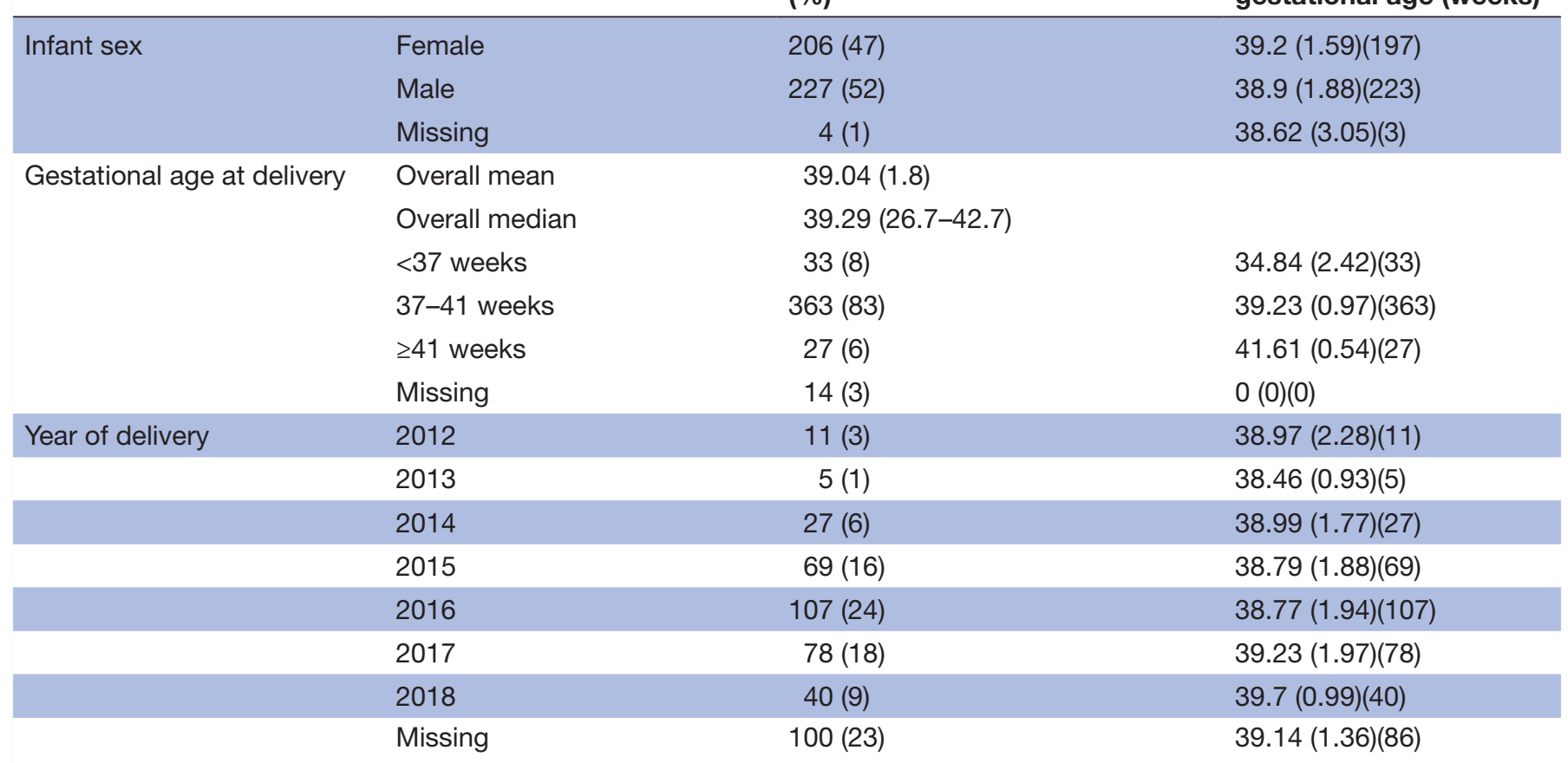

*Indicates significant association between birth weight and demographic characteristic $(p<0.05)$. CRECE, Centre for Research on Early Childhood Exposure and Development.
Mean (SD)(N) gestational age (weeks)

$(1.88)(223)$

$39.04(1.8)$

$-42.7$

$0(0)(0)$

$6(0.93)(5)$

$38.79(1.88)(69)$

$39.14(1.36)(86)$
$34.84(2.42)(33)$ $\mu \mathrm{g} / \mathrm{m}^{3}$. More detailed reporting on the $\mathrm{PM}_{2.5}$ levels can be found in Kirwa et al. ${ }^{71}$

Summary statistics and one-sample t-tests comparing geometric means of urinary biomarkers between the mothers of CRECE participants and US women aged 18-40 participating in the National Health and Nutrition Examination Survey (NHANES) cohort (measured in 2009-2010, 2011-2012, 2013-2014) are presented in table 4. Mothers of CRECE participants had significantly higher urinary concentrations of 24-DCP, 25-DCP, TCS and TCC, but significantly lower levels of BPF, MPB, EPB and PPB compared with US female NHANES participants of childbearing age.

In summary, our initial findings do not show any significant associations between maternal demographics and gestational age. We have not currently assessed enough preterm infants to make meaningful comparisons between term/preterm status and birth and developmental outcomes measured as NNS, BDI, APGAR and AGD scores. Initial comparisons of maternal urinary biomarkers of measured phenols and parabens show some differences compared with mainland US female NHANES participants of childbearing age. Ambient $\mathrm{PM}_{2.5}$ levels in the study area were also lower than those found in the conterminous US. Next steps will focus on identifying associations between mixtures of environmental contaminants and birth and developmental outcomes and incorporating the repeated measures of these exposures and outcomes for a more complete analysis.

\section{COTC and parent engagement}

A major innovative element of our COTC is our extensive and rigorous report-back strategies. Relatively few environmental health researchers report individual research data back to their participants, and NIEHS is increasingly supportive of this approach. Report-back to participants of their environmental health data is important for several reasons: it affirms an ethical 'rightto-know' about research in which a person has participated, it provides personalised data on known and/or potential hazards and how to mitigate or prevent them, and it empowers individuals and communities to become more effective in advocating for improved public health services and environmental protections. ${ }^{72}$ Moreover, this approach is science education/research translation in action. A further innovation is that we carry out this report-back with an interdisciplinary team of environmental health scientists and social scientists, who can collectively contribute to a broader social, community, neighbourhood and political economic context for people facing known or suspected hazards. ${ }^{73}$ Through the COTC's role as the public interface for CRECE, our innovative community-driven efforts bring together residents, government, researchers, physicians and other healthcare providers, and community organisations to create better dialogue and practice around children's environmental health, both for our study participants and the whole Island. Furthermore, CRECE ensures highquality report-back of individual data to participants, and 


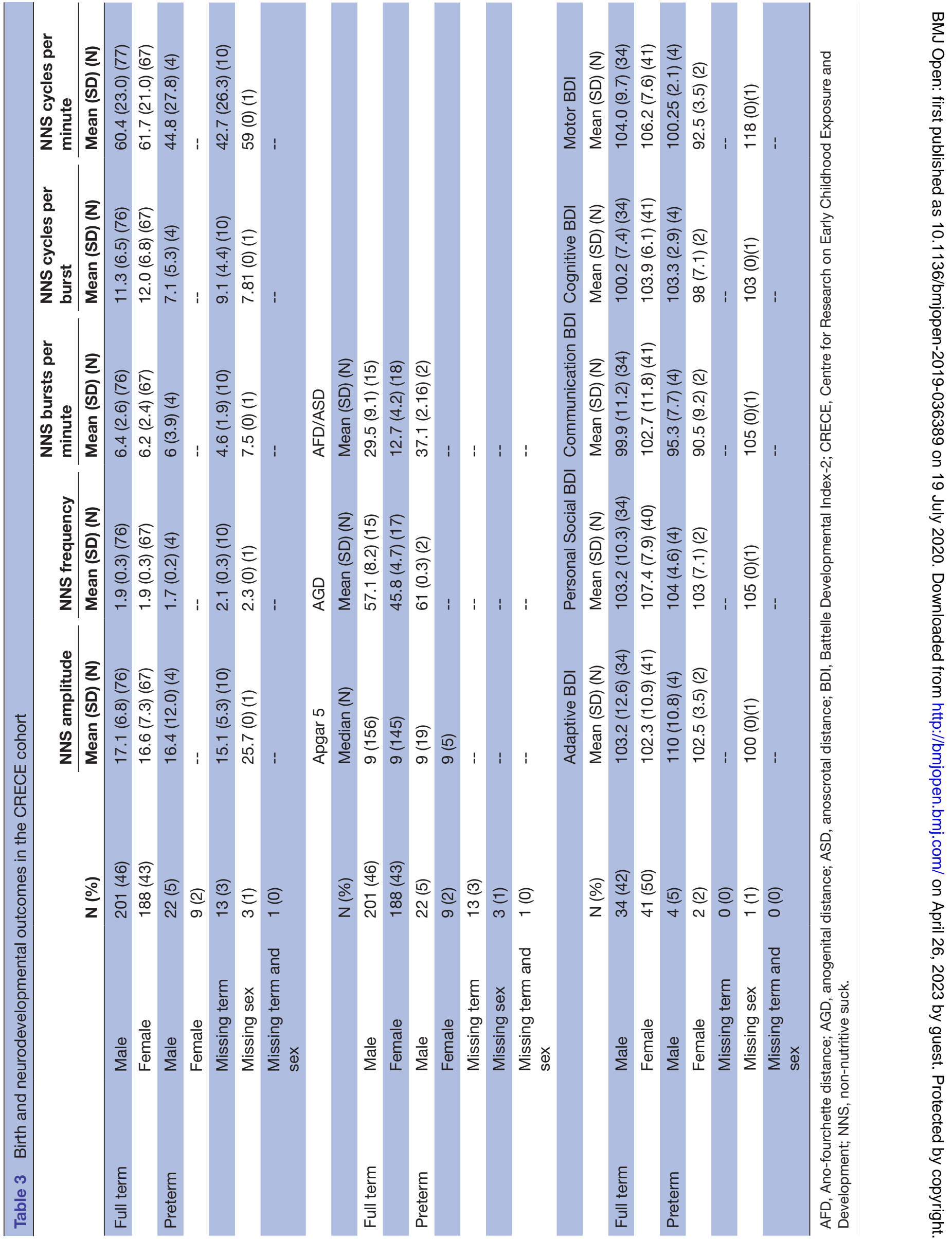


Table 4 Urinary biomarker concentrations $(\mathrm{ng} / \mathrm{mL})$ in pregnant women participating in the CRECE cohort and comparison with US women ages $18-40$ participating in NHANES

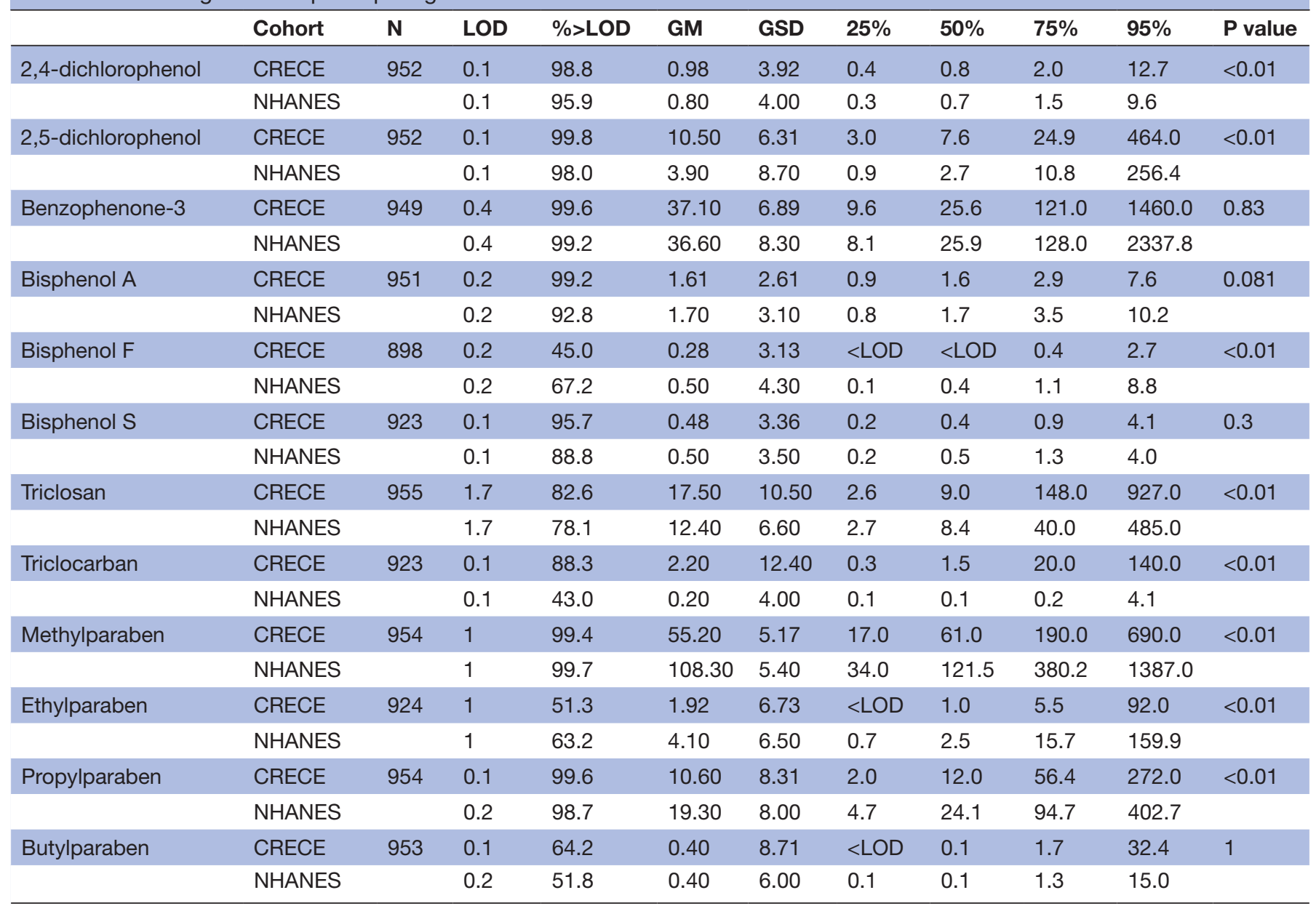

$P$ value corresponds to a one-sample t-test using the NHANES concentrations as reference values.

CRECE, Centre for Research on Early Childhood Exposure and Development; GM, geometric mean; GSD, geometric standard deviation; LOD, limit of detection; NHANES, National Health and Nutrition Examination Survey.

aggregate data to communities, in collaboration with the Human Subjects Core and the project investigators. The report-back process for CRECE participants is ongoing and dynamic, as it is tailored to the specific needs of the study participants and their parents. At every visit where physical examination, measurements and/or neurodevelopmental assessment are done, the mother/parent receives feedback of the results. In case of the identification of signs of a developmental delay, behavioural problem and/or other concerning physical finding, the research team explains the finding to the parent, provides the parent with information for the participants' primary healthcare provider, and if necessary or requested by the parent and with the parent's writen consent, contacts the child's healthcare provider directly. We also provide participants with a multisection portfolio to keep copies of report back documents so parents' have the information they may need to facilitate the child's navigation of the early intervention service system. The information provided to participants' parents includes guidelines for the child's expected developmental milestones, as well as suggested stimulation activities to help the child along. In the case of identification of signs of developmental delay or other health concerns, the researchers give parents appropriate guidance to inform the child's primary healthcare provider who is in charge of the appropriate attention and follow-up. The research team conducts meetings with paediatricians, paediatric subspecialists, paediatric psychologists, occupational, physical, speech and language therapists and other developmental early intervention providers in the study area, to provide general information about the CRECE study and what kind of feedback should be facilitated to participants parents in order to support their access to early intervention services, and specialty care if needed. We organise voluntary educational activities and provide materials on early childhood development and stimulation to participants' parents who wish to take part.

\section{Strengths and limitations}

This study has many strengths_-innovative aims involving early-life exposure to phenols, parabens and mixtures 
and their relationship to fetal and child development; study of an at-risk and underserved population that will provide valuable information for public health policy to better protect at-risk populations and can generate other hypothesis for future research studies in the area of paediatric environmental health; access to rich datasets and samples from the ongoing cohort study; cost-efficiency; statistical innovation; a valuable source of information and support for the study population; and a low attrition rate.

There are also a number of limitations. First, our study population is Hispanic and located in Puerto Rico, potentially impacting the generalisability of our results. However, our study will add new, important information on exposures and child development and includes biomarkers of intermediate effect to provide mechanistic clues. When interpreted along with collected toxicity data, results can provide strong human evidence for whether an exposure impacts development. Though our findings might not be generalisable to the whole US population, they may be generalisable to similarly vulnerable populations.

Importantly, our enrolment period overlapped with the Zika epidemic and several hurricanes, including Hurricane Maria in 2017. For the hurricanes, the PROTECT and CRECE centres were very active in the recovery; collaborating with various organisations to ensure the safety and welfare of team members, study participants, community health centre partners and members of the surrounding communities. The study teams have multiple research partners who provided support to obtain urgent and necessary supplies and medicine for the communities in the study area. The PROTECT and CRECE team provided over 500 emergency packs for pregnant women and mothers of young children. Another potential weakness is limiting the exposure assessment to the gestation period. In addition to logistical constraints associated with systematically collecting urine or blood from infants and young children, there are budget constraints due to the high cost of exposure biomarkers. However, we do not expect there to be confounding of the relationship with fetal exposure and development by exposure in childhood, as we and others have demonstrated a lack of correlation between in utero and childhood exposure to CECs. ${ }^{74}{ }^{75}$ Furthermore, fetal development may be a more sensitive period compared with childhood for impacts of CEC exposures on many developmental outcomes as we have shown in another study of reproductive development. ${ }^{76-78}$

\section{SUMMARY AND CONCLUSIONS}

Several features of this cohort provide an unprecedented opportunity for addressing important public health concerns among an at-risk, underserved population. This is the first study to assess the relationships between in utero exposures to most of these chemicals of concern, preterm birth and a range of child development endpoints. This study incorporates repeated measures of exposure, intermediate effect and outcome variables for a more robust analysis than the limited previous studies of exposure to CECs and fetal/child development. In addition, we will provide much needed data on the relationship between phenols and parabens and endocrine function, oxidative stress and inflammation-mechanisms which may mediate a range of adverse health effects beyond those being assessed in the proposed study.

\section{Author affiliations}

${ }^{1}$ Department of Health Sciences, Northeastern University, Boston, Massachusetts, USA

${ }^{2}$ Department of Communication Sciences and Disorders, Northeastern University, Boston, Massachusetts, USA

${ }^{3}$ Department of Environmental Health Sciences, University of Michigan School of Public Health, Ann Arbor, Michigan, USA

${ }^{4}$ University of Puerto Rico Graduate School of Public Health, University of Puerto Rico Medical Sciences Campus, San Juan, Puerto Rico

${ }^{5}$ Department of Civil and Environmental Engineering, Northeastern University, Boston, Massachusetts, USA

${ }^{6}$ Department of Civil and Environmental Engineering, Tufts University, Medford, Massachusetts, USA

${ }^{7}$ School of Civil and Environmental Engineering, Cornell University, Ithaca, New York, USA

${ }^{8}$ Department of Sociology and Anthropology, Northeastern University, Boston, Massachusetts, USA

${ }^{9}$ Social Science Environmental Health Research Institute, Northeastern University,

Boston, Massachusetts, USA

${ }^{10}$ Department of Epidemiology and Biostatistics, University of Georgia, Athens, Georgia, USA

Contributors All authors listed meet the ICMJE requirements for authorship. Additionally, AA, JM, JFC, PB, AZG, HS, CV-V, EZ and JM were involved in the conception and design of the study. JM,EZ, DW, TC, ZR, ZF and MO were involved in the data analysis and interpretation. CV-V, GH-M, ZR, IA, CV and PB were involved in recruitment and data collection. JM and EZ drafted the manuscript. All authors critically revised this article and approved the final version.

Funding Funding for this work was supported by the National Institute of Enviromental Health Sciences, National Institute of Health (P50ES026049, P42ES017198), the Environmental Protection Agency (EPA Assistance Agreement Number 83615501), and the Environmental influences on Child Health Outcomes (ECHO) program, a nationwide research program supported by the National Institutes of Health (NIH), Office of the Director to enhance child health (UH3 0D023251).

Map disclaimer The depiction of boundaries on this map does not imply the expression of any opinion whatsoever on the part of BMJ (or any member of its group) concerning the legal status of any country, territory, jurisdiction or area or of its authorities. This map is provided without any warranty of any kind, either express or implied.

Competing interests None declared.

Patient consent for publication Not required.

Ethics approval The research protocol for PROTECT was approved by the Ethics and Research Committees of the University of Puerto Rico and participating clinics, the University of Michigan and Northeastern University.

Provenance and peer review Not commissioned; externally peer reviewed.

Data availability statement Data are available on reasonable request. Direct access to the data is not permitted without the expressed permission of the approving human research ethics committees and data custodians. Researchers interested in collaboration should contact the corresponding author with their expression of interest.

Open access This is an open access article distributed in accordance with the Creative Commons Attribution Non Commercial (CC BY-NC 4.0) license, which permits others to distribute, remix, adapt, build upon this work noncommercially, and license their derivative works on different terms, provided the original work is properly cited, appropriate credit is given, any changes made 
indicated, and the use is non-commercial. See: http://creativecommons.org/ licenses/by-nc/4.0/

ORCID iD

Justin Manjourides http://orcid.org/0000-0002-2454-4489

\section{REFERENCES}

1 Pérez-Perdomo R, Pérez-Cardona C, Disdier-Flores O, et al. Prevalence and correlates of asthma in the Puerto Rican population: behavioral risk factor surveillance system, 2000. J Asthma 2003;40:465-74

2 Ortega AN, McQuaid EL, Canino G, et al. Association of psychiatric disorders and different indicators of asthma in island Puerto Rican children. Soc Psychiatry Psychiatr Epidemiol 2003;38:220-6.

3 Lara M, Akinbami L, Flores G, et al. Heterogeneity of childhood asthma among Hispanic children: Puerto Rican children bear a disproportionate burden. Pediatrics 2006;117:43-53.

4 Findley S, Lawler K, Bindra M, et al. Elevated asthma and indoor environmental exposures among Puerto Rican children of East Harlem. J Asthma 2003;40:557-69.

5 Mo D. Premature birth report card for Puerto Rico 2018, 2018. Available: https://www.marchofdimes.org/peristats/tools/reportcard. aspx?frmodrc $=1 \&$ reg $=72$ [Accessed 11 Jan 2019].

6 Martin JA, Hamilton BE, Osterman MJK, et al. Births : final data for 2017. U.S: National Center for Health Statistics, 2018.

7 Yu X, Feric Z, Cordero JF, et al. Potential influence of temperature and precipitation on preterm birth rate in Puerto Rico. Sci Rep 2018;8:16106.

8 Szentpetery SE, Forno E, Canino G, et al. Asthma in Puerto ricans: lessons from a high-risk population. J Allergy Clin Immunol 2016;138:1556-8.

9 Rosas-Salazar C, Ramratnam SK, Brehm JM, et al. Prematurity, atopy, and childhood asthma in Puerto ricans. J Allergy Clin Immunol 2014:133:357-62.

10 Rosas-Salazar C, Forno E, Brehm JM, et al. Breastfeeding duration and asthma in Puerto Rican children. Pediatr Pulmonol 2015;50:527-34.

11 Lewis LM, Mirabelli MC, Beavers SF, et al. Characterizing environmental asthma triggers and healthcare use patterns in Puerto Rico. J Asthma 2019:1-12 (Epub 2019/06/13).

12 Ferguson KK, Rosen EM, Rosario Z, et al. Environmental phthalate exposure and preterm birth in the protect birth cohort. Environ Int 2019;132:105099.

13 Ferguson KK, Chen Y-H, VanderWeele TJ, et al. Mediation of the relationship between maternal phthalate exposure and preterm birth by oxidative stress with repeated measurements across pregnancy. Environ Health Perspect 2017;125:488-94.

14 Klecka G, Persoon C, Currie R. Chemicals of emerging concern in the great lakes Basin: an analysis of environmental exposures. Rev Environ Contam Toxicol 2010;207:1-93.

15 EPA. Search for Superfund sites where you live, 2019. Available: https://www.epa.gov/superfund/search-superfund-sites-where-youlive [Accessed 11 Jan 2019].

16 Zhu X, Liu Y, Chen Y, et al. Maternal exposure to fine particulate matter (PM2.5) and pregnancy outcomes: a meta-analysis. Environ Sci Pollut Res Int 2015;22:3383-96.

17 Wilson AM, Wake CP, Kelly T, et al. Air pollution, weather, and respiratory emergency room visits in two Northern new England cities: an ecological time-series study. Environ Res 2005;97:312-21.

18 Perera FP, Rauh V, Whyatt RM, et al. A summary of recent findings on birth outcomes and developmental effects of prenatal Ets, PAH, and pesticide exposures. Neurotoxicology 2005;26:573-87.

19 Miranda ML, Edwards SE, Chang HH, et al. Proximity to roadways and pregnancy outcomes. J Expo Sci Environ Epidemiol 2013;23:32-8.

20 Lee P-C, Roberts JM, Catov JM, et al. First trimester exposure to ambient air pollution, pregnancy complications and adverse birth outcomes in Allegheny County, PA. Matern Child Health $J$ 2013;17:545-55.

21 Lai H-K, Tsang H, Wong C-M. Meta-Analysis of adverse health effects due to air pollution in Chinese populations. BMC Public Health 2013;13:360.

22 Fleischer NL, Merialdi M, van Donkelaar A, et al. Outdoor air pollution, preterm birth, and low birth weight: analysis of the world Health organization global survey on maternal and perinatal health. Environ Health Perspect 2014;122:425-30.

23 Cândido da Silva AM, Moi GP, Mattos IE, et al. Low birth weight at term and the presence of fine particulate matter and carbon monoxide in the Brazilian Amazon: a populationbased retrospective cohort study. BMC Pregnancy Childbirth 2014;14:309

24 Brauer M, Lencar C, Tamburic L, et al. A cohort study of trafficrelated air pollution impacts on birth outcomes. Environ Health Perspect 2008;116:680-6

25 Bell ML, Belanger K, Ebisu K, et al. Prenatal exposure to fine particulate matter and birth weight: variations by particulate constituents and sources. Epidemiology 2010;21:884-91.

26 Orazzo F, Nespoli L, Ito K, et al. Air pollution, aeroallergens, and emergency room visits for acute respiratory diseases and gastroenteric disorders among young children in six Italian cities. Environ Health Perspect 2009;117:1780-5.

27 Hafström M, Kjellmer I. Non-Nutritive sucking by infants exposed to pethidine in utero. Acta Paediatr 2000;89:1196-200.

28 Estep M, Barlow SM, Vantipalli R, et al. Non-Nutritive suck parameter in preterm infants with RDS. J Neonatal Nurs 2008;14:28-34.

29 Boutin-Forzano S, Adel N, Gratecos L, et al. Visits to the emergency room for asthma attacks and short-term variations in air pollution. A case-crossover study. Respiration 2004;71:134-7.

30 Diamanti-Kandarakis E, Bourguignon J-P, Giudice LC, et al. Endocrine-Disrupting chemicals: an endocrine Society scientific statement. Endocr Rev 2009;30:293-342.

31 Meeker JD. Exposure to environmental endocrine disruptors and child development. Arch Pediatr Adolesc Med 2012;166.

32 Avilés LA, Alvelo-Maldonado L, Padró-Mojica I, et al. Risk factors, prevalence trend, and clustering of hypospadias cases in Puerto Rico. J Pediatr Urol 2014;10:1076-82.

33 Colón I, Caro D, Bourdony CJ, et al. Identification of phthalate esters in the serum of young Puerto Rican girls with premature breast development. Environ Health Perspect 2000;108:895-900.

34 Larriuz-Serrano MC, Pérez-Cardona CM, Ramos-Valencia G, et al. Natural history and incidence of premature thelarche in Puerto Rican girls aged 6 months to 8 years diagnosed between 1990 and 1995 . $P$ $R$ Health Sci J 2001;20:13-18.

35 Bellinger D, Dietrich KN. Low-Level lead exposure and cognitive function in children. Pediatr Ann 1994;23:600-5.

36 Lanphear BP, Hornung R, Khoury J, et al. Low-Level environmental lead exposure and children's intellectual function: an international pooled analysis. Environ Health Perspect 2005;113:894-9.

37 Needleman HL, Gatsonis CA. Low-Level lead exposure and the IQ of children. A meta-analysis of modern studies. JAMA 1990;263:673-8.

38 Kang S, Kim S, Park J, et al. Urinary paraben concentrations among pregnant women and their matching newborn infants of Korea, and the association with oxidative stress biomarkers. Sci Total Environ 2013;461-462:214-21.

39 Miao M, Yuan W, Zhu G, et al. In utero exposure to Bisphenol-A and its effect on birth weight of offspring. Reprod Toxicol 2011;32:64-8.

40 Blumenshine P, Egerter S, Barclay CJ, et al. Socioeconomic disparities in adverse birth outcomes: a systematic review. Am J Prev Med 2010;39:263-72.

41 Tong S, Baghurst P, Vimpani G, et al. Home environment, and cognitive development. J Pediatr 2007;151:284-8.

42 King S, Laplante DP. The effects of prenatal maternal stress on children's cognitive development: project ice storm. Stress 2005;8:35-45.

43 Larsen AD, Schlünssen V, Christensen BH, et al. Exposure to psychosocial job strain during pregnancy and odds of asthma and atopic dermatitis among 7-year old children - a prospective cohort study. Scand J Work Environ Health 2014;40:639-48.

44 Shapiro GD, Fraser WD, Frasch MG, et al. Psychosocial stress in pregnancy and preterm birth: associations and mechanisms. $J$ Perinat Med 2013;41:631-45.

45 Edwards SC, Jedrychowski W, Butscher M, et al. Prenatal exposure to airborne polycyclic aromatic hydrocarbons and children's intelligence at 5 years of age in a prospective cohort study in Poland. Environ Health Perspect 2010;118:1326-31.

46 Jedrychowski WA, Perera FP, Camann D, et al. Prenatal exposure to polycyclic aromatic hydrocarbons and cognitive dysfunction in children. Environ Sci Pollut Res Int 2015;22:3631-9.

47 Suglia SF, Gryparis A, Wright RO, et al. Association of black carbon with cognition among children in a prospective birth cohort study. Am J Epidemiol 2008;167:280-6.

48 Ostro BD, Feng W-Y, Broadwin R, et al. The impact of components of fine particulate matter on cardiovascular mortality in susceptible subpopulations. Occup Environ Med 2008;65:750-6.

49 Sacks JD, Stanek LW, Luben TJ, et al. Particulate matter-induced health effects: who is susceptible? Environ Health Perspect 2011;119:446-54.

50 Evans AM, Rice GE, Teuschler LK, et al. Joint exposure to chemical and nonchemical neurodevelopmental stressors in U.S. women 
of reproductive age in NHANES. Int J Environ Res Public Health 2014;11:4384-401.

51 White LD, Cory-Slechta DA, Gilbert ME, et al. New and evolving concepts in the neurotoxicology of lead. Toxicol Appl Pharmacol 2007;225:1-27.

52 Evans GW, Kim P. Childhood poverty and health: cumulative risk exposure and stress dysregulation. Psychol Sci 2007;18:953-7.

53 Kristenson M, Eriksen HR, Sluiter JK, et al. Psychobiological mechanisms of socioeconomic differences in health. Soc Sci Med 2004;58:1511-22.

54 Seed J, Brown RP, Olin SS, et al. Chemical mixtures: current risk assessment methodologies and future directions. Regul Toxicol Pharmacol 1995;22:76-94.

55 Silva E, Rajapakse N, Kortenkamp A. Something from "nothing"-eight weak estrogenic chemicals combined at concentrations below NOECs produce significant mixture effects. Environ Sci Technol 2002;36:1751-6.

56 Ferguson KK, Rosario Z, McElrath TF, et al. Demographic risk factors for adverse birth outcomes in Puerto Rico in the protect cohort. PLoS One 2019;14:e0217770.

57 Cohen S, Kamarck T, Mermelstein R. A global measure of perceived stress. J Health Soc Behav 1983;24:385-96.

58 Allabadi H, Alkaiyat A, Alkhayyat A, et al. Depression and anxiety symptoms in cardiac patients: a cross-sectional hospital-based study in a Palestinian population. BMC Public Health 2019;19:232.

59 Swan SH. Environmental phthalate exposure in relation to reproductive outcomes and other health endpoints in humans. Environ Res 2008;108:177-84.

60 Swan SH, Main KM, Liu F, et al. Decrease in anogenital distance among male infants with prenatal phthalate exposure. Environ Health Perspect 2005;113:1056-61.

61 ISO I. 9835, ambient air-Determination of a black smoke index. Geneva: International Organization for Standardization, 1993.

62 Calafat AM, Valentin-Blasini L, Ye X. Trends in exposure to chemicals in personal care and consumer products. Curr Environ Health Rep 2015;2:348-55.

63 Screening infants and young children for developmental disabilities. American Academy of pediatrics Committee on children with disabilities. Pediatrics 1994;93:863-5.
64 Schonhaut L, Armijo I, Schönstedt M, et al. Validity of the ages and stages questionnaires in term and preterm infants. Pediatrics 2013;131:e1468-74.

65 Moraleda-Barreno E, Romero-López M, Cayetano-Menéndez MJ. [The Battelle developmental inventory screening test for early detection of developmental disorders in cerebral palsy]. An Pediatr 2011;75:372-9.

66 Odent MR. Synthetic oxytocin and breastfeeding: reasons for testing an hypothesis. Med Hypotheses 2013;81:889-91.

67 Rose SA, Feldman JF, Jankowski JJ. The building blocks of cognition. J Pediatr 2003;143:54-61.

68 Rose S, Feldman JF, Futterweit LR. Continuity in visual recognition memory: infancy to 11 years. Intelligence 1997;24:381-92.

69 Kovács Ágnes Melinda, Téglás E, Endress AD. The social sense: susceptibility to others' beliefs in human infants and adults. Science 2010;330:1830-4.

70 ÁM K. Belief files in theory of mind Reasoning. Review of Philosophy and Psychology 2016;7:509-27.

71 Kirwa K, McConnell-Rios R, Manjourides J, et al. Low birth weight and $\mathrm{PM}_{25}$ in Puerto Rico. Environ Epidemiol 2019;3:e058.

72 Brody JG, Morello-Frosch R, Brown P, et al. Improving disclosure and consent: "is it safe?": new ethics for reporting personal exposures to environmental chemicals. Am J Public Health 2007;97:1547-54.

73 Brown P, Brody JG, Morello-Frosch R, et al. Measuring the success of community science: the Northern California household exposure study. Environ Health Perspect 2012;120:326-31.

74 Lewis RC, Meeker JD, Peterson KE, et al. Predictors of urinary bisphenol $\mathrm{A}$ and phthalate metabolite concentrations in Mexican children. Chemosphere 2013;93:2390-8.

75 Hoepner LA, Whyatt RM, Just AC, et al. Urinary concentrations of bisphenol $A$ in an urban minority birth cohort in New York City, prenatal through age 7 years. Environ Res 2013;122:38-44.

76 Wright RO, Environment WRO. Environment, susceptibility windows, development, and child health. Curr Opin Pediatr 2017;29:211-7.

77 Watkins DJ, Téllez-Rojo MM, Ferguson KK, et al. In utero and peripubertal exposure to phthalates and BPA in relation to female sexual maturation. Environ Res 2014;134:233-41.

78 Ferguson KK, Peterson KE, Lee JM, et al. Prenatal and peripubertal phthalates and bisphenol $A$ in relation to sex hormones and puberty in boys. Reprod Toxicol 2014;47:70-6. 